\title{
CUIDADOS DE ENFERMAGEM NOS CASOS DE ANSIEDADE NA ATENÇÃO PRIMÁRIA À SAÚDE: REVISÃO DE LITERATURA
}

\author{
Alessandra Aparecida Tavares Neves ${ }^{1}$; Michelle Taverna ${ }^{2}$ \\ ${ }^{1}$ Enfermeira, Universidade Federal de São Paulo (UNIFESP), Curitiba, Paraná. \\ ${ }^{2}$ Enfermeira, Universidade Tuiuti do Paraná (Tuiuti), Curitiba, Paraná.
}

DOI: 10.47094/IICNNESP.2021/10

\begin{abstract}
RESUMO
O Brasil é o país com maior taxa de pessoas com transtorno de ansiedade do mundo, atingindo cerca de 18,6 milhões de brasileiros (Organização Mundial de Saúde - OMS, 2018). O enfermeiro é apto para identificar e intervir nas situações de ansiedade e o objetivo deste estudo foi identificar os principais cuidados de enfermagem nos casos de ansiedade já na atenção primária à saúde. Para tanto, foi conduzida uma revisão integrativa de literatura nas bases de dados indexadas na Biblioteca Virtual em Saúde (BVS) e localizados 99 artigos, após análise 10 artigos atenderam aos critérios de inclusão. Dentre as publicações investigadas, observamos que as propostas eram diferentes entre os estudos. Conclui-se que a ansiedade é um problema de saúde pública em ascensão e por isso é imprescindível o desenvolvimento pesquisas mais amplas com enfoque nas intervenções terapêuticas mundiais com melhores resultados para o tratamento da ansiedade.
\end{abstract}

PALAVRAS-CHAVE: Ansiedade. Cuidados de enfermagem. Atenção primária à saúde.

ÁREA TEMÁTICA: Saúde física e mental.

\section{INTRODUÇÃO}

O transtorno de ansiedade é uma condição na qual existe uma preocupação exacerbada, recorrente, pensamentos distorcidos e pessimistas. A resposta fisiológica a esse estado causa angústia e aflição ao indivíduo, o que acarreta em busca de atendimento no pronto socorro. O enfermeiro é apto para identificar e intervir nas situações de ansiedade na atenção primária à saúde, promovendo um cuidado integrado aos pacientes e familiares (OLIVEIRA; MARQUES; SILVA, 2020).

Diante a importância que o tema representa para o papel do enfermeiro, este estudo teve como objetivo identificar os cuidados de enfermagem nos casos de ansiedade nos pacientes atendidos na atenção primária à saúde. 


\section{METODOLOGIA}

O método de pesquisa selecionado foi a revisão integrativa de literatura. Desse modo, buscamos responder a seguinte pergunta norteadora: Quais são as evidências disponíveis na literatura científica sobre os cuidados de enfermagem nos casos de ansiedade nos pacientes atendidos na atenção primária à saúde?

A busca dos artigos ocorreu por meio da base de dados indexados na Biblioteca Virtual em Saúde (BVS). Para a localização dos mesmos foram utilizados os seguintes descritores controlados: "ansiedade", "cuidados de enfermagem", "atenção primária à saúde”. Realizamos a combinação das palavras-chave da seguinte maneira: "ansiedade" and "cuidados de enfermagem" and "atenção primária à saúde". Os critérios de inclusão foram os artigos que abordaram quaisquer cuidados de enfermagem relacionados à ansiedade na atenção primária à Saúde e artigos publicados em português, inglês e espanhol no período de janeiro de 2011 a junho de 2021. Assim, foram localizados 99 artigos na base de dados investigada, sendo que após análise apenas 10 artigos atenderam aos critérios de inclusão previamente estabelecido. A análise dos dados foi conduzida por dois revisores independentemente, através de um instrumento de coleta de dados definido pelos próprios autores.

\section{RESULTADOS E DISCUSSÕES}

Dentre as publicações investigadas, observamos que as propostas eram diferentes entre os estudos. Dois artigos (20\%) abordaram a primeira etapa do processo de enfermagem: Avaliação de enfermagem; um (10\%) versava sobre o Reiki como intervenção de enfermagem; um (10\%) discorria sobre a promoção e gerenciamento do autocuidado; um (10\%) relatou sobre: Criar Oportunidades para Empoderamento Pessoal (COPE), um (10\%) evidenciou o método da atenção plena (Mindfulness) como aliada na assistência, um (10\%) abordou sobre o uso da terapia cognitiva comportamental e uso de medicações para controle da ansiedade e três (30\%) sugeriram o cuidado escalonado colaborativo como ferramenta na assistência.

No que se refere às intervenções propostas, percebemos que o processo de enfermagem é uma ferramenta muito valiosa na atenção primária, pois o enfermeiro pautado em evidências científicas, a partir do histórico de enfermagem correlaciona os problemas levantados com o propósito de saná-los através da prescrição de enfermagem (COFEN, 2009).

O Reiki é uma terapia complementar usada para redução do estresse e relaxamento. Essa técnica japonesa é desenvolvida por um profissional habilitado e conforme a resolução COFEN-197/1997, o enfermeiro pode aplicar essa metodologia na assistência prestada (FREITAG; ANDRADE; BADKE, 2015).

O conjunto de ações que um indivíduo realiza para si mesmo é denominado de autocuidado. A teoria de Dorothea Orem ressalta a importância do paciente ser o protagonista do cuidar, para tanto é necessário que o enfermeiro conheça a teoria do autocuidado e direcione o paciente a executar as ações de maneira que assuma a responsabilidade para contribuir com o tratamento (SILVA, et al., 
O programa COPE (Criando Oportunidades para Empoderamento Pessoal) é um programa de desenvolvimento de habilidades cognitivo-comportamentais para adolescentes de 13 a 18 anos. $\mathrm{O}$ objetivo do COPE é fornecer educação, informações e atividades para ajudar os adolescentes a fazerem escolhas saudáveis que levarão a uma vida saudável. Guiado pela teoria cognitivo-comportamental, o programa visa ajudar os adolescentes a aprender as habilidades de que precisam (por exemplo, pensamento positivo, habilidades de enfrentamento, gerenciamento de estresse, atenção plena) para parar os pensamentos negativos e começar a pensar e se comportar de maneiras mais positivas (NIH, 2021).

Atenção plena ou Mindfulness é um estado de plenitude promovido a partir da escolha sólida e determinada do indivíduo para tomar conhecimento do que está ocorrendo no seu interior e exterior, sendo capaz de envolver-se no presente, sem manifestar desvios de atenção. O Mindfulness como intervenção de enfermagem envolve a integralidade do cuidar, promovendo estratégias eficazes (GHERARDI-DONATO, et al., 2019).

Os tratamentos farmacológicos devem ser acompanhados para diminuir a preocupação devido à dependência química, física e psicológica que podem desenvolver devido ao uso abusivo e prolongado. É importante destacar que não deve ser adotado como tratamento único. A terapia Cognitivo-Comportamental é uma aliada ao tratamento, visto que evidencia uma redução dos sintomas e atua de maneira efetiva, porém essas medidas são exclusivas de outros profissionais, não sendo aplicadas pelo enfermeiro (OLIVEIRA; MARQUES; SILVA, 2020).

O cuidado escalonado colaborativo é uma junção de intervenções que proporcionam a interdisciplinaridade que contribuem para a qualidade da assistência. $\mathrm{O}$ apoio matricial é um modelo com similaridade ao cuidado colaborativo e é uma realidade no Brasil, este modelo utiliza o papel da referência e contra referência para integrar o cuidado, ampliando o acesso da atenção primária à atenção secundária. Para tanto, deve haver um treinamento e planejamento da equipe para definição do programa (SARAIVA; ZEPEDA; LÍRIA, 2020).

\section{CONCLUSÕES}

A ansiedade é um problema de saúde pública e tem grande repercussão na sociedade. A atenção primária à saúde deve contribuir ativamente no diagnóstico e tratamento precoce dos pacientes, destacamos a extrema importância do papel do enfermeiro neste processo com ações de enfermagem que promovem o aumento da qualidade de vida desses pacientes. Consenso na literatura, o Brasil precisa progredir em suas políticas de ações intervencionistas através do desenvolvimento amplo pesquisas a respeito das melhores práticas mundiais para o tratamento da ansiedade. 


\section{REFERÊNCIAS}

Conselho Federal de Enfermagem. Resolução n. 358, de 15 de outubro de 2009: Dispõe sobre a Sistematização da Assistência de Enfermagem e a implementação do Processo de Enfermagem. Disponível em: http://www.cofen.gov.br/resoluo-cofen-3582009_4384.html. Acesso em: 06 jun.2021.

FREITAG, V. L.; ANDRADE, A. de; BADKE, M. R. O Reiki como forma terapêutica no cuidado à saúde: uma revisão narrativa da literatura, Enfermería Global, n. 38, p. 346, abr. 2015. Disponível em: https://scielo.isciii.es/pdf/eg/v14n38/ptrevision5.pdf. Acesso em: 06 jun.2021.

GHERARDI-DONATO, E. C. da S. et al. Mindfulness: reflexão sobre limites e potencialidades para a assistência de enfermagem. Rev. Enferm. UFSM - REUFSM. Santa Maria, RS, v. 9, e52, p. 1-21, 2019. Disponível em: https://periodicos.ufsm.br/reufsm/article/view/33058/html. Acesso em: 06 jun.2021.

National Cancer Institute at the National Institutes of Health (NIH). Disponível em: https://ebccp. cancercontrol.cancer.gov/programDetails.do?programId=22686590. Acesso em: 06 jun.2021

OLIVEIRA, K. M. A. de; MARQUES, T. C.; SILVA, C. D. A. Cuidados de enfermagem frente ao transtorno de ansiedade. Revista das Ciências da Saúde e Ciências aplicadas do Oeste Baiano-Higia, v. 5, n. 1, p. 397-412, 2020. Disponível em: file://C:/Users/ALESSA 1/AppData/Local/Temp/6121989-1-PB.pdf. Acesso em: 06 jun.2021.

Organização Mundial da Saúde - OMS. Ficha técnica - Depressão. Disponível em: http://www.who. int/mental_health/management/depression Acesso em: 09 jun. 2021.

SARAIVA, S. A. L.; ZEPETA, J.; LIRIA, A. F. Componentes do apoio matricial e cuidados colaborativos em saúde mental: uma revisão narrativa. Ciência \& Saúde Coletiva, v. 25, n. 2 p. 553565, fev. 2020. Disponível em: https://www.researchgate.net/publication/339012705_Componentes_ do_apoio_matricial_e_cuidados_colaborativos_em_saude_mental_uma_revisao_narrativa. Acesso em: 06 jun.2021. 